\title{
Estado, política y cuestión militar entre 1880 y 1890. El Partido Autonomista Nacional y la organización de un nuevo Ejército de la Nación
}

Artículo recibido: 17 de octubre de 2019 Aprobación final: 06 de abril de 2020

\begin{abstract}
Resumen
El artículo analiza las características, alcances y límites de algunas reformas encaradas durante las dos primeras presidencias del Partido Autonomista Nacional (1880-1890) para centralizar el manejo de las fuerzas militares, desmilitarizar a la sociedad y disminuir los niveles de violencia política. Con ese fin examina el tratamiento de los proyectos legislativos de reclutamiento del Ejército y enrolamiento de la Guardia Nacional y otras medidas administrativas que buscaron en esos años organizar la remonta de los ejércitos nacionales y diseñar un nuevo perfil del soldado-ciudadano.
\end{abstract}

Palabras clave: Estado, ejército, Partido Autonomista Nacional, Congreso Nacional, centralización.

State, Politics and the Military Reforms between 1880 and 1890. The National Autonomist Party and the Organization of the National Army in Argentina

\begin{abstract}
This article analyses the features, scope and limits of the reforms undertaken during the first two presidencies held by the National Autonomist Party (18801890) to centralize the management of military forces, demilitarize society and reduce the levels of political violence. To that end, I review bills and administrative reforms regarding Army recruitment, drafting into the National Guard, and
\end{abstract}


other administrative actions seeking to organize the national armies and create a new citizen-soldier.

Keywords: State, army, National Autonomist Party, National Congress, centralization.

\section{Introducción}

La llegada al poder presidencial en 1880 del Partido Autonomista Nacional (PAN, en adelante) de la mano de Julio A. Roca, tras una conflictiva sucesión que enfrentó a los poderes nacionales y a la provincia de Buenos Aires, es considerada habitualmente un punto de inflexión en la construcción del estado argentino. La vasta literatura disponible sobre esa coyuntura ha señalado que dos medidas sancionadas en el marco de ese conflicto -la federalización de la ciudad de Buenos Aires y la prohibición a los gobiernos de provincia de formar fuerzas militaresfueron hitos decisivos en la centralización del estado y en la consolidación de las instituciones nacionales que permitieron que el PAN se abocara en los años siguientes a la persecución del "progreso". ${ }^{1}$

Este trabajo pone el foco en una dimensión de ese proceso de transformación del Estado y de la política que se dio en los años ochenta, a partir del análisis de las medidas que el Poder Ejecutivo diseñó y llevó a cabo para reorganizar las fuerzas militares durante y tras la crítica coyuntura de 1880. Miradas en su conjunto, esas propuestas impulsadas por los presidentes y ministros de Guerra -en especial por Roca- estuvieron orientadas a obtener un dominio creciente del Poder Ejecutivo Nacional sobre esas fuerzas, de la mano de una centralización en el comando nacional y un aumento del control del ejército profesional y permanente sobre las tropas de reserva compuestas por milicianos civiles (las llamadas guardias nacionales). Para alcanzar ese objetivo, la nueva administración nacional debía avanzar sobre funciones cumplidas hasta ese momento por las provincias, lo cual se erigió en un importante escollo para alcanzar logros sustantivos en el nuevo diseño militar. ${ }^{2}$

En las páginas que siguen analizo las características, alcances y límites de esas reformas encaradas por los gobiernos del PAN para centralizar el manejo de las fuerzas militares, desmilitarizar a la sociedad y disminuir los niveles de violencia política. ${ }^{3}$ Abordo el tratamiento de las leyes que procuraron centralizar las

1 Es muy amplia la bibliografía sobre los cambios que tuvieron lugar en torno a 1880 en la organización del estado y en el funcionamiento de la política. Entre las obras de las últimas décadas que sirven de marco para los debates más actuales: Botana (1977 y 1993); Botana y Gallo (1997); Halperin Donghi (1980); Oszlak (1982); Sabato (1998); Gerchunoff et al. (2007); Alonso (2010). Sobre la organización de las agencias estatales en esta etapa, fueron especialmente inspiradores para este trabajo: Zimmermann (1995); Bohoslavsky y Soprano (2010); Plotkin y Zimmermann (2012).

2 En la línea de la legislación que fue sancionada posteriormente en la década de 1890. Sobre este punto, véanse especialmente: Forte (2003); Soprano et al. (2012); Quinterno (2014); Guembe (2015); Avellaneda (2017b).

3 EI PAN era una constelación de dirigencias provinciales que a fines de los años setenta se había articulado para promover la candidatura de Roca. Como ha mostrado la reciente historiografía sobre este tema, en su interior convivían sectores políticos muy diversos que se hallaban en permanente negociación y confrontación. Durante la década de 1880, los dos presidentes que provinieron del partido tuvieron a su 
fuerzas milicianas, los proyectos de reclutamiento del Ejército y enrolamiento de la Guardia Nacional -que fueron constantemente aplazados por el Congreso-, ${ }^{4} \mathrm{y}$ otras medidas administrativas relativas a la remonta del Ejército en las provincias. Sobre la base de ese análisis empírico señalo que tanto el diseño y aplicación de las leyes efectivamente sancionadas en materia de centralización como la negativa del Congreso a tratar varios proyectos que abordaban el reclutamiento de ciudadanos tuvieron dos consecuencias importantes. Por una parte, aumentaron los obstáculos para que el gobierno nacional recortara la capacidad militar de las provincias, pues estas retuvieron parte de su poderío militar, así como participación en el reclutamiento del Ejército y de las guardias. Por otra, impidieron avanzar de manera decidida en la separación de las guardias nacionales respecto de los conflictos políticos que atravesaban a sus localidades, y, en función de ello, alcanzar transformaciones más profundas en la pacificación de la política. Este resultado se vinculó a que, a pesar de los esfuerzos oficiales para que la instrucción de los milicianos fuera llevada a cabo por el ejército profesional lejos de sus localidades, aquella siguió en mano de los comandantes milicianos y anudada de ese modo a las dinámicas políticas de cada espacio.

En la primera sección presento el diseño y práctica militar durante las llamadas décadas de "organización nacional" para entender cuáles eran los problemas que los gobiernos de los años ochenta buscaban resolver. En las siguientes, examino el trámite parlamentario de las leyes militares sancionadas al calor de los conflictos de 1880 y las reformas militares impulsadas durante las presidencias de Julio Argentino Roca (1880-1886) y Miguel Juárez Celman (1886-1890). En todos los casos, exploro las razones que dieron origen a esas iniciativas, las controversias y tensiones que desataron dentro del Congreso (y entre los legisladores y los miembros del Poder Ejecutivo), así como la dinámica cambios de maniobra y de prueba y error que esos disensos provocaron en la política militar que efectivamente logró llevar a cabo la coalición gobernante durante esa década. Por último, vuelvo sobre algunos conflictos armados que se dieron esos años para ensayar un balance sobre cuál fue la profundidad en las transformaciones de las normas y de las prácticas.

Finalmente, en las conclusiones pondero los resultados que esta investigación pueden tener para revisar algunas cuestiones históricas que confluyen en la temática aquí analizada: las características del Estado nacional en esa etapa de su consolidación frente a los estados provinciales; las relaciones entre el Poder Ejecutivo y Legislativo en lo que hace a la reglamentación de aspectos clave del sistema político como la organización militar; y la dinámica político-partidaria de esa década en el marco del sistema de partido hegemónico del PAN.

vez estilos políticos disímiles y plantearon formas distintas de relación entre el gobierno nacional y las provincias (Alonso, 2010). A lo largo de este trabajo, se muestran diferencias que se dieron dentro de esta constelación en materia de ideas relativas a la organización militar y se plantean algunos interrogantes sobre cómo su dinámica interna se cruzó con el funcionamiento institucional del Ejecutivo y el Congreso. 


\section{La cuestión militar durante la “organización nacional” (1853-1880)}

En las últimas décadas, la historiografía ha revisado el funcionamiento de las instituciones militares durante la etapa de construcción del Estado, así como sus conexiones con las formas de hacer la política. Ha contestado las miradas que postulaban una concentración escalonada de los recursos militares hasta alcanzar el monopolio de la violencia en 1880, y ha mostrado que la experiencia de ciudadanía en armas resultó una parte constitutiva de la organización política de la Argentina y de la formación de una comunidad política nacional. ${ }^{5}$ Esta literatura ha señalado que la Carta nacional sancionada en 1853 dejó atrás el modelo de organización militar confederal que había predominado en los años de funcionamiento autónomo de las provincias tras las guerras de independencia, y procuró edificar un Ejército Nacional sobre la base de dos instituciones distintas. Por una parte, el Ejército de Línea, de servicio regular e integrado por oficiales de carrera y por soldados enganchados y destinados, que dependía del Poder Ejecutivo Nacional. Por otra, un ejército de reserva, la Guardia Nacional compuesta por ciudadanos, que también era dependiente del presidente como comandante en jefe, pero que en la práctica era administrado por los gobernadores. ${ }^{6}$ Esa elección se fundó en el poder militar con que habían contado los estados provinciales durante la etapa confederal, en un escenario en el que el Estado nacional carecía de poder suficiente para imponer una concentración del manejo de la fuerza militar.Pero también, esa compleja combinación de dos sistemas militares fue defendida por parte de la clase política con el argumento de que el funcionamiento de una Guardia Nacional de ciudadanos permitía mantener un ejército permanente reducido y evitar el uso de esa fuerza para la erección de un poder de tipo absoluto. Ese diseño provocó importantes desafíos para la estabilidad política: los cuerpos militares ciudadanos estuvieron íntimamente conectados con las dinámicas políticas de sus respectivas localidades y esa dualidad en materia jurisdiccional entre provincias y Nación fomentó controversias y choques militares entre las dos esferas a lo largo de la segunda mitad del siglo XIX.?

Hubo en esos años algunos intentos infructuosos de reglamentar de manera más precisa las fuerzas militares y cumplir con la prescripción constitucional que encargaba al Congreso disponer de su organización, armamento y disciplina. Pero esas iniciativas derivaron en disputas políticas y doctrinarias que condujeron a distintos consensos prácticos, que se fueron modificando de manera continua. Una de las principales reglamentaciones militares se dictó durante la presidencia

5 Una puesta al día en: Canciani (2012); Macías y Sabato (2013); Codesido (2016).

$6 \mathrm{El}$ art. 67 fijaba entre las atribuciones del Congreso: "Autorizar la reunión de las milicias de todas las provincias o parte de ellas, cuando lo exija la ejecución de las leyes de la Nación y sea necesario contener las insurrecciones o repeler las invasiones. Disponer la organización, armamento y disciplina de dichas milicias, y la administración y gobierno de la parte de ellas que estuviese empleada en servicio de la Nación, dejando a las provincias el nombramiento de sus correspondientes jefes y oficiales, y el cuidado de establecer en su respectiva milicia la disciplina prescripta por el Congreso". Es decir, que una vez movilizada, la guardia pasaba en teoría a jurisdicción de la nación, aunque en la práctica quedó muchas veces en manos de los gobernadores. También la Corte Suprema defendió en esos años las prerrogativas provinciales en materia de administración y gobierno de las milicias. Codesido (2016: 63 y 177). Varias provincias conservaron en esa etapa tropas provinciales para las tareas de mantenimiento del orden interno. Macías y Sabato (2013: 73).

7 Especialmente: Sabato (2008); Míguez (2011). 
de Sarmiento (1868-1874), como consecuencias de las deficiencias en materia organizativa que había hecho evidente la Guerra de la Tripe Alianza contra el Paraguay. ${ }^{8}$ Se trataba de la primera ley de reclutamiento del Ejército, sancionada en 1872 y que continuó en vigencia hasta el fin de siglo. Hasta ese momento, la falta de una ley en la materia había dificultado enormemente la remonta del Ejército. La nueva normativa detallaba las características del reclutamiento de voluntarios y enganchados, así como las de la incorporación de los destinados y contingentes. ${ }^{9}$ Incluía, también, un sistema de sorteo universal de los guardias nacionales enrolados por provincia para completar las plazas que requiriera el Ejército de Línea, pero ese sistema no se reglamentó ni aplicó hasta 1887, en función de las desavenencias que generó con las provincias (Domínguez, 1898, Tomo 3: 225-226). ${ }^{10}$

La ley de 1872 formaba parte de un programa de modernización militar encarado por Sarmiento que tuvo en general resultados dispares (Macías, 2014 y 2018; Codesido, 2016). Aunque la profesionalización del Ejército y la Marina recibieron un impulso decisivo con la creación del Colegio Militar y de la Escuela Naval Militar -que buscaba vincular a los hombres de armas con la nación en ciernes y desarmar sus conexiones con la política de sus localidades-, otras medidas tendentes a la despolitización y profesionalización de las fuerzas militares fueron menos exitosas. ${ }^{11}$ En 1873 Sarmiento presentó un proyecto, basado en la legislación norteamericana, para limitar la influencia de jefes y oficiales del ejército y marina en las elecciones (Sarmiento, 1902: 341-2). Este proyecto ingresó a la cámara de Diputados y pasó a Comisión de Legislación, pero luego se interrumpió su trámite parlamentario. Al año siguiente, el alzamiento mitrista volvió a poner en el centro de las preocupaciones del gobierno la cuestión militar. El entonces presidente Nicolás Avellaneda (1874-1880) procuró avanzar en la reglamentación del Ejército con un proyecto de Ordenanzas Generales redactado por una Comisión compuesta por Lucio Mansilla, Dardo Rocha y José Ignacio Garmendia (que finalmente no tuvo tratamiento legislativo), y con un decreto de 1875 que creaba ocho intendencias en el país para poder supervisar desde el Ministerio de Guerra el reclutamiento del Ejército y no depender tanto de los gobiernos de provincia, con lo cual intentaba dar un paso en la centralización del control de las fuerzas militares (Codesido, 2016: 191 y 280). En función de esas mismas preocupaciones, en el marco de la reforma de la ley electoral de 1877 se logró un consenso parlamentario para eliminar el requisito de estar enrolado para poder votar, al tiempo

8 Conflagración que había, de todos modos, fortalecido al Ejército como institución, junto con las campañas militares para la represión de los alzamientos del interior. Codesido (2016: 123-4); Comando en Jefe del Ejército (1971:121).

9 Domínguez, 1898, Tomo 2: 421-423. Para el enrolamiento de la Guardia Nacional, que debía formar eventualmente los contingentes enviados al Ejército de Línea, regía la ley del 5 de junio de 1865, que declaraba el enrolamiento obligatorio de los argentinos casados entre 17 y 45 y solteros entre 45 y 50 años (Comando en Jefe del Ejército,1971: 81).

10 La ley de 1872 fue acompañada por dos disposiciones complementarias, que buscaban regular tanto el Ejército de Línea como las milicias ciudadanas: el Decreto 1371 sobre la Remonta del Ejército de Línea y el 1372 que estipulaba las características de la organización de la Guardia Nacional.

11 Hasta ese momento, la carrera militar carecía de formación sistemática y no resultaba incompatible con otras ocupaciones de la vida pública. 
que varias reformas de las constituciones provinciales incluyeron explícitamente prescripciones para alejar a las milicias de los actos electorales (Macías, 2016).

Esas modificaciones se dieron en el marco de los temores que provocaba que la sucesión presidencial de 1880 derivara, como la de 1874, en un conflicto militar. En esta instancia se enfrentaron dos candidatos. Julio Roca, que se desempeñaba como ministro de Guerra y estaba llevando su campaña de avance de la frontera hasta el Río Negro, y Carlos Tejedor, gobernador de Buenos Aires, quien denunció la injerencia electoral del Gobierno nacional y proclamó que resistiría tal imposición oficial con el apoyo de las guardias de Buenos Aires. Esta medida profundizó el conflicto entre el Gobierno provincial y el nacional en las discusiones respecto de las facultades de los gobiernos de provincia en materia de organización, disciplina y movilización de la Guardia Nacional que poblaron los debates de la legislatura de la provincia de Buenos Aires, la prensa y el Congreso de la Nación a fines de 1879.

\section{Los debates del ochenta: disputas por la centralización militar en el Congreso}

De cara a las confrontaciones que amenazaban desatarse con la sucesión de 1880, Sarmiento, entonces ministro del Interior, presentó al Congreso un proyecto de ley, que fijaba que hasta tanto el Congreso dictara una ley orgánica de reorganización y disciplina de la Guardia Nacional, esta solo podía ser convocada por el Poder Ejecutivo Nacional y no por los gobiernos de provincia. Esos gobiernos debían, además, licenciar los batallones militares que funcionaran en sus jurisdicciones y tendrían prohibido dar organización militar a sus fuerzas de policía (Argentina, 1879: 700). El proyecto señalaba la vacancia normativa derivada de que el Congreso no había dictado aún una ley reglamentaria y se proponía resolver provisoriamente el espinoso tema de las incumbencias militares entre nación y provincias. ${ }^{12}$ Aunque el objetivo urgente era desarmar los recursos materiales que tenía en esa coyuntura el gobernador de la provincia de Buenos Aires para contestar el poder del Estado nacional, en un sentido más general y de largo plazo, apuntaba a sentar doctrina en la materia.

Las preocupaciones del Ejecutivo, expresadas por el ministro, no fueron compartidas por la mayoría del Congreso. La Comisión de Negocios Constitucionales de Diputados (presidida por el expresidente Bartolomé Mitre) alteró sustancialmente el proyecto. ${ }^{13}$ En su reformulación no se prohibía expresamente a las provincias

12 Esta cuestión estaba siendo debatida simultáneamente en la Legislatura de Buenos Aires en el marco de un proyecto de movilización de las fuerzas de la provincia (Sabato, 2008).

13 Quedó sancionado con esta redacción: “Art. 1. La prohibición del artículo 59 de la ley de 16 de Octubre de 1877, queda estendida a los ejercicios doctrinales de la guardia nacional durante la época de inscripción en el Rejistro Cívico y ocho meses antes de la elección de electores de Presidente de la República, bajo las penas en dicha ley establecidas. Art $2^{\circ}$. Las fuerzas de policía de las Provincias no estarán sujetas a las penas de la ordenanza militar. $3^{\circ}$ El conocimiento y decisión de las causas por falta de enrolamiento corresponde exclusivamente a los Tribunales federales, quienes procederán sumariamente. Art. $4^{\circ}$ Comuníquese" (Argentina, 1896: 179). 
movilizar a la Guardia Nacional. Tampoco se explicitaba que las provincias debían desarmar sus batallones provinciales, ni se fijaba que el Poder Ejecutivo Nacional tenía facultades exclusivas en esa materia. Por el contrario, la Comisión argumentó, no sin ironía, que la mejor forma de evitar insurrecciones en la sucesión presidencial era ampliando las libertades electorales. Esta propuesta reforzaba además la defensa de las garantías individuales al establecer la jurisdicción federal para faltas en materia de enrolamiento (Argentina, 1879: 838-842). Al llegar al Senado, la Comisión de Guerra y Marina recomendó aprobar la ley con las revisiones introducidas por la Cámara Baja. ${ }^{14}$ De ese modo, fracasó el objetivo de Sarmiento. El Congreso, en encendidos debates que fueron seguidos de cerca por la prensa, ${ }^{15}$ rechazó las interpretaciones del Ejecutivo sobre las facultades militares de las provincias, se negó a aumentar las potestades militares del presidente y respondió a ese afán de concentración militar con una ampliación expresa de libertades y garantías ciudadanas. ${ }^{16}$ Como era previsible, la sanción de la ley no clausuró las controversias, porque desde el inicio se presentó como "una disposición transitoria" que por otra parte resultó muy difícil de hacer cumplir en las provincias (Argentina, 1879: 727). En los meses siguientes, los conflictos por las incumbencias militares de las dos esferas no cesaron, sino que por el contrario se mostraron con toda virulencia en el choque armado entre las fuerzas de la provincia de Buenos Aires y el Ejército de la Nación en las jornadas de junio de 1880 (Sabato, 2008).

Luego de la derrota porteña, una de las primeras medidas presidenciales apuntó a revertir la dispersión militar que posibilitaba ese tipo de alzamientos. Avellaneda presentó al Senado, en septiembre de 1880, el proyecto de ley que prohibía a las autoridades de provincia la formación de cuerpos militares bajo cualquier denominación. Entonces el presidente echó en cara a las Cámaras no haber sancionado el año anterior la ley con la redacción propuesta por Sarmiento, ya que consideraba que de ese modo se hubiera evitado el derramamiento de sangre de

14 La Comisión intentó sin éxito introducir una modificación adicional que hubiera dejado abierta la posibilidad de que las provincias levantaran ejércitos en casos de peligro inminente, al fijar como excepción el caso previsto por el artículo 108 de la Constitución (que las autoridades provinciales podrían armar buques de guerra y levantar ejércitos en caso de invasión exterior o peligro inminente que no admitiera dilación). También se presentó un proyecto en minoría, firmado por otros miembros de la comisión -Rafael Igarzabal y Leónidas Echagüe- que proponía sancionar el texto aprobado por Diputados, pero agregando en el artículo $1^{\circ}$ que la prohibición regía hasta tres meses después de la instalación del nuevo gobierno (Argentina, 1879: 700).

15 La Nación reprodujo a diario las polémicas y fijó su posición contestataria frente a la propuesta del Ejecutivo. Sostuvo que las leyes militares de la etapa confederal, y con ellas las prerrogativas militares de las provincias, seguían vigentes al no haber sido derogadas por el Congreso; que la Suprema Corte de Justicia de la Nación había fallado en el mismo sentido, para lo cual reprodujo una decisión de ese tribunal de 1868; que la legislación norteamericana e inglesa sostenía el derecho de las provincias/estados para movilizar por sí mismos milicia para mantener el orden interno; y que incluso para cuestiones nacionales era el Congreso, y no el Poder Ejecutivo, quien podía disponer esa movilización (con lo cual, de paso, el diario disputaba el alcance de los constitucionales poderes de guerra del Presidente). Véase: La Nación, 6, 11, 13, 20 y 21 de septiembre de 1879. La Prensa prestó menos atención a esta discusión y se pronunció tempranamente en contra de las facultades provinciales en materia militar. La Prensa, 7 de septiembre y 8 de octubre de 1879.

16 Quienes lideraron la oposición a la redacción dada por Sarmiento fueron el diputado por Córdoba, Cayetano Lozano y el senador por Corrientes, Juan Eusebio Torrent, que apoyaban la candidatura de Tejedor. Del lado opuesto, se destacaron las intervenciones de los senadores por Santa Fe, Manuel Pizarro, y por Buenos Aires, Aristóbulo del Valle, más cercanos en ese momento a la coalición que sostenía a Roca. Una lectura distinta de los resultados del debate en relación con las intenciones de Sarmiento en Codesido (2016: 335-338). 
junio de ese año (Argentina, 1880:581). ${ }^{17}$ La Comisión Militar de la Cámara Alta introdujo leves modificaciones, que fueron aceptadas por el ministro de Guerra, Carlos Pellegrini, quien se hallaba presente en el recinto. ${ }^{18}$ Tanto el miembro informante de la Comisión -el senador por San Juan perteneciente al PAN, Agustín Gómez-, como el ministro, insistieron en la necesidad de que las provincias desmilitarizaran sus fuerzas de policía. Las gendarmerías provinciales debían funcionar como instituciones civiles, formadas por empleados estatales y no por ciudadanos-milicianos armados (o peor aún, por individuos que habían sido condenados al servicio de armas por delitos que la gendarmería venía precisamente a combatir) (Argentina, 1880b: 448).

Contra ese consenso entre la Comisión y el ministro, otros senadores volvieron a traer a colación el siempre problemático artículo 108 de la Constitución, que preveía que las provincias armaran ejércitos en casos de extrema urgencia, e insistieron en que la ley dijera "la prohibición de cuerpos militares permanentes". Esta inclusión hubiera dejado abierta, una vez más, la posibilidad de que las provincias movilizaran tropas contra las autoridades nacionales y fue rápidamente minada por Gómez y Pellegrini. El proyecto de ley fue aprobado (con las modificaciones introducidas por la comisión de guerra) y remitido a Diputados, donde la Comisión Militar llevó el debate a una cuestión de hermenéutica constitucional. El miembro informante, el santafesino Pedro Reyna, se interrogó por la necesidad misma de sancionar una ley en la materia,y apuntó a los intersticios de la Carta nacional donde se condensaba el grueso de la función reglamentaria del Congreso:

¿La existencia de esos batallones de guardias provinciales, que tienen algunas provincias, es o no constitucional [...]? Si no hay precepto constitucional que prohíba la existencia de esos batallones, no hay derecho a imponer a los Estados la disolución de esos cuerpos, y, si hay un precepto constitucional que no los autorice, entonces, señor Presidente, ¿para qué vamos a dictar una ley [...]? (Argentina, 1880b: 430)

Esas dilaciones de la Cámara Baja ponían al Poder Ejecutivo en una posición complicada, en la medida en que ya había suprimido de hecho los batallones de Buenos Aires tras los enfrentamientos armados de junio de ese año "y pondría en la necesidad a la nueva administración, de hacer volver ese batallón o batallones de que ha dispuesto, y entregarlos aquí al gobernador de la Provincia” (Argentina: 1880b: 432). Del lado opuesto, varios diputados protestaron por las consecuencias que tendría para el futuro dar una ley orgánica (que reglamentaba un principio constitucional) no sobre la base de fundados estudios sino por las impresiones de un hecho excepcional como había sido la conflagración armada de $1880 .{ }^{19}$ En

17 La misma recriminación en El Nacional, 18 de julio de 1880. El Proyecto original, firmado por Pellegrini, ministro de Guerra de Avellaneda, decía que los batallones provinciales quedaban incorporados al ejército nacional y prohibía a las autoridades de provincia la formación de nuevos cuerpos, bajo cualquier denominación (Argentina, 1880: 484).

18 Permitía que los milicianos pidieran la baja del ejército para no ser absorbidos por el Ejército de Línea, salvo los que estuvieran destinados al Ejército por condena judicial o infracción a la ley de enrolamiento. La comisión estaba compuesta por Santiago Baibene (Corrientes), Agustín Gómez (San Juan) y Manuel Navarro (Catamarca).

19 Véase, especialmente, el discurso de Sáenz Peña. 
ese marco general, la discusión giró más concretamente sobre tres temas que ya habían aparecido en los días previos: primero, si las provincias tenían o no derecho a armar cuerpos para mantener su orden interno y si debía tratarse de cuerpos militares o de policía. Segundo, si los batallones, que en la práctica existían en casi todas las provincias, ${ }^{20}$ eran constitucionales o inconstitucionales, punto que una vez más fue objeto de diferencias irreconciliables. Tercero, si la nacionalización de los batallones que impulsaba el Ejecutivo implicaba convertir a los guardias nacionales de las provincias en soldados de Línea, y si esto resultaba atentatorio de sus derechos individuales.

Tras encendidos enfrentamientos verbales, apenas 32 diputados contra 28 decidieron aprobar el proyecto en general, para que pudiera tratarse en 1880. En la cámara se impuso así la posición de quienes buscaban sancionar una ley que evitara la repetición de los sucesos de junio de ese año. Para ese resultado, fue decisivo que 40 diputados -en general opositores a Roca- hubieran sido cesanteados por no haberse trasladado a Belgrano junto con las autoridades nacionales en el marco del conflicto armado, y posteriormente reemplazados con la elección de legisladores alineados con el PAN. Pero incluso muchos diputados que apoyaban en general el proyecto disentían con la redacción elegida por el Poder Ejecutivo Nacional y aprobada por el Senado. Las razones que esgrimieron fueron que no estaba entre las atribuciones del Congreso permitir o prohibir a las provincias tener fuerzas de policía y que la ley socavaba derechos individuales de los milicianos que serían absorbidos por el Ejército de Línea. ${ }^{21}$ A lo largo del debate se plantearon numerosas reformulaciones, pero ninguna alcanzó la cantidad necesaria de votos. Finalmente, se aprobó solo una sección del primer artículo y el proyecto de ley quedó reformulado de manera mínima: "Queda prohibido a las autoridades de Provincia la formación de cuerpos militares” (Argentina, 1880b: 443-4).

Al día siguiente el Senado lo trató en revisión, rechazó las modificaciones de Diputados e insistió en su redacción original para impedir que las provincias organizaran fuerzas militares, cualquiera fuera su nombre (Argentina, 1880: 674682). ${ }^{22}$ De modo que el proyecto retornó a la Cámara de Diputados y el ministro de Guerra volvió a ser convocado al recinto (Argentina, 1880b: 475). Entonces ya había asumido Roca y el ministro no era Pellegrini, el iniciador del proyecto, sino Benjamín Victorica, cuya defensa de la iniciativa fue más vacilante. Se limitó a afirmar que el espíritu de la ley era que las provincias no tuvieran cuerpos militares permanentes, pero que resultaba completamente legal que tuvieran guardias nacionales. Algunos diputados, celosos de las autonomías provinciales, aprovecharon la confusión o permisión del ministro para que la ley dijera en su letra que solo prohibía a las provincias contar con cuerpos de Línea. No obstante, a esa

20 El ministro de Guerra indicó que se trataba de doce batallones provinciales de más o menos 200 plazas cada uno.

$21 \mathrm{Y}$ que tampoco estaba entre las atribuciones del Senado iniciar leyes que hacían al reclutamiento de tropas, como dictaba la Constitución en su artículo 44.

22 Las opciones en esa instancia se reducían a aceptar una u otra redacción o a suprimir algún artículo, pero estos no podían ser alterados de ninguna manera. 
altura de la revisión el reglamento impedía cambiar la redacción. Por eso, Diputados insistió en su sanción anterior por 38 votos contra $13 .{ }^{23}$ Ese mismo día el proyecto volvió al Senado, que aceptó la supresión de los artículos 2 y 3 hecha por la Cámara Baja, porque, como expresó el senador Aristóbulo del Valle, lo urgente de la ley se hallaba en su primer artículo y los demás generaban más resistencia, incluso entre los senadores que ya no podían modificar su redacción, dada la aprobación inicial (Argentina, 1880: 691). ${ }^{24}$ Pero justamente por la importancia de ese primer artículo, el Senado rechazó la reformulación mínima de Diputados y la sancionó con la leyenda "bajo cualquier denominación que sea”. Dos días después, la Ley 1.072 fue promulgada, mientras los legisladores que habían cerrado su labor anual con esta espinosa cuestión volvían a sus respectivas provincias. ${ }^{25}$

El Senado logró así imponer la redacción final del artículo único de la ley, solo porque la Cámara iniciadora tenía ventaja reglamentaria sobre la revisora. Sin embargo, no todo fue un triunfo. Como socarronamente señalaba La Nación, que en ese momento practicaba un ejercicio muy moderado de oposición en el marco de la vigencia del estado de sitio, el proyecto de ley de 1880 había sido mucho más modesto que la iniciativa de Sarmiento de $1879,{ }^{26}$ e incluso la versión finalmente sancionada había sido aún más reducida. Solo se logró aprobar el artículo $1^{\circ} \mathrm{y}$ debió desistirse de los artículos 2 y 3 que formaban parte del proyecto original. ¿Qué pasó entre la iniciación del proyecto por parte de Avellaneda y Pellegrini y su promulgación por Roca y Victorica? ¿Por qué Diputados no dejó morir el proyecto con la simple estrategia de no tratarlo ese año? De las manifestaciones hechas en la Cámara y en la prensa se deduce que los diputados consideraron mejor sancionar al menos una medida provisoria de desmilitarización, que aplazar el asunto hasta que se lograran los consensos necesarios en todos los aspectos que tocaba la cuestión militar (el régimen federal, las facultades reglamentarias del Congreso en lo militar, los derechos individuales de los milicianos-soldados). El Senado, por su parte, se conformó con el artículo $1^{\circ}$, porque prefirió resignar las otras cuestiones por aquella que consideraba la más importante: terminar con la descentralización militar que agravaba la inestabilidad política. ${ }^{27}$ Parte de esas negociaciones en el Congreso se entablaron más allá del recinto, en la antesala, donde los legisladores se hallaron de manera casi permanente esperando que una y otra Cámara desalojaran el espacio para poder sesionar, ${ }^{28}$ junto con los

23 Se encontraban presentes 51 de los 82 diputados que debían integrar la Cámara Baja. Catorce de ellos (diez provenientes de Buenos Aires, tres de Corrientes y uno de Jujuy) apenas se habían iniciado en el puesto hacía una semana. Otros 25 se habían incorporado unos meses antes por las elecciones de comienzos de 1880, y 12 estaban en la Cámara desde 1878. Ibid., p. 495.

24 Esto sugiere también (16 de octubre de 1880), El Nacional. Véase, además, (17 de octubre de 1880), La Prensa. Al igual que El Nacional, La Prensa apoyó desde el primer momento este proyecto de ley pero le dio menos tratamiento que La Nación.

25 Al momento de la votación se hallaban 17 de los 28 senadores en el recinto. La totalidad de Jujuy, San Luis, Tucumán, Salta, Entre Ríos, Santiago del Estero. Faltaban uno por Catamarca, uno por Santa Fe, uno por Corrientes, uno por San Juan, uno por Buenos Aires, dos por La Rioja y dos por Córdoba.

26 (17 de Octubre de 1880), La Nación. Sobre los efectos del estado de sitio en su prédica, véase el número del 30 de Octubre.

27 Esta posición fue resumida en el conocido discurso de Del Valle: “¿A qué objeto útil han servido los batallones que han tenido las provincias? ¿A qué objeto útil pueden responder en adelante? Solo han servido como elemento de perturbación en la República" (Argentina, 1880: 676).

28 En teoría debían sesionar simultáneamente y terminar al mismo tiempo, y en una no se podía 
miembros del Ejecutivo que se habían dirigido a allí para ser interrogados, escuchar los debates y convencer a los parlamentarios. Con todo, a pesar de que el proyecto había sido mutilado en el Legislativo, sirvió a los objetivos más inmediatos del Ministerio de Guerra y unos días después el decreto 11.719 mandó licenciar el batallón Guardia Provincial de Buenos Aires, para conciliar la ley con los hechos (Argentina, 1896: 334)..$^{29}$

Luis Sommariva ha resumido una mirada generalizada sobre la ley 1.072 al señalar que su sanción se dio bajo el "enajenamiento del triunfo" (1931:108).Sin embargo, su tratamiento parlamentario no solo evidencia los conflictos y negociaciones políticas e institucionales que acompañaron su aprobación, sino que también muestra los disensos en materia de diseño militar entre las dirigencias provinciales que se nucleaban en el PAN. ${ }^{30}$ Esa ley solo reglamentó en parte el artículo 108 de la Constitución que tantos desacuerdos había despertado en las décadas previas en lo que hacía a las facultades militares de nación y provincias, pero no saldó las controversias sobre la cuestión militar por otros dos motivos. Por una parte, porque el gobierno nacional tuvo muchas dificultades para hacerla cumplir en todo el territorio, como el propio estudio de Sommariva mostró. Por otra, porque esa norma no constituía una ley reglamentaria sobre organización, armamento y disciplina de la Guardia Nacional como había dispuesto la Constitución. Esos dos factores explican en parte las coordenadas en que se desenvolvió en los años siguientes la política militar del PAN, como se trata a continuación.

\section{El modelo de servicio compulsivo de ciudadanos para un nuevo Ejército nacional}

Desde el comienzo de su mandato, Julio Roca trató de lograr vastas reformas militares. Luego de decretar una reorganización de toda la Guardia Nacional a fines del $1880,{ }^{31}$ impulsó una batería de leyes en 1881: Ley de reclutamiento del Ejército y enrolamiento de la Guardia Nacional, Ley de Ascensos, ${ }^{32}$ Ley de Organización de

mencionar lo que se había dicho en la otra. Por falta de espacio, no se cumplía esa disposición (Argentina, 1880: 691).

29 En 1881 el Poder Ejecutivo Nacional organizó un nuevo enrolamiento para la Capital Federal (con arreglo a ley de 5 de junio de 1865) y nombró nuevos Jefes de los regimientos de la ciudad (Domínguez, 1898, Tomo 3: 5-7). También reorganizó la Guardia Nacional en la provincia de Buenos Aires, y la $1^{\circ}$ División del Ejército destinada a la guarnición de la Capital (4 batallones de Infantería, 1 Regimiento de Artillería y otro de Caballería en que se refundió la Escolta del Presidente) (Argentina, 1881: VIII).

30 Los debates fueron liderados en el Senado por Aristóbulo del Valle (Buenos Aires), Francisco Ortiz (Salta), Aureliano Argento (Santa Fe) y Agustín Gómez (San Juan), todos ellos alineados entonces en la coalición de dirigencias que formaba el PAN. La discusión en Diputados fue más coral. Allí se destacaron las intervenciones de Adolfo Dávila (La Rioja), Luis Lagos García, Luis Sáenz Peña y Nicolás Calvo (Buenos Aires), Tristán Achával Rodríguez (Córdoba), José Vicente Saravia (Entre Ríos), Delfín Gallo (Buenos Aires) y Pedro Lucas Funes (Santa Fe). Entre ellos, el único partidario de la oposición era Dávila.

31 “Decreto 10 de Diciembre de 1880" (Argentina, 1896: 347). Y a lo largo de su presidencia nombró a importantes dirigentes de su partido -entre ellos el propio ministro de Guerra Carlos Pellegrini- como Jefes de los Regimientos de la ciudad de Buenos Aires para evitar que los opositores tuvieran mando de tropa (Domínguez, 1898: Tomo 3, 148-9 y 159-60).

32 Resultaba importante para superar un uso partidario de las promociones que iba más allá de favorecer a los propios. El ascenso de jefes del partido opositor como prenda de negociación y de incorporación al gobierno había sido usado en el pasado para amortiguar las disputas partidarias (Codesido, 2014). 
los Ejércitos de la República y Ley de reformas, retiros y pensiones. La primera de ellas, que tenía por objeto derogar la normativa de 1872 y detallar de manera más exhaustiva cómo debía llevarse adelante el reclutamiento del Ejército y el enrolamiento de la Guardia Nacional, fue la que recibió más atención por parte del presidente. Roca consideraba necesaria una completa reorganización de la fuerza militar, pues hasta el momento el Ejército estaba en gran parte compuesto por destinados que cumplían en sus filas una pena y, en mucha menor medida, por enganchados voluntariamente por "patriotismo" o "vocación a la carrera militar". Consideraba que la ley debía asegurar que el conjunto de los ciudadanos afrontara la carga común del servicio de armas y delineaba el rol que a su criterio debían tener las fuerzas milicianas, lejos de aquellas arengas que habían poblado el Congreso, la prensa y las recientes batallas de 1880 sobre su papel de guardianes de la libertad y herramienta popular frente al despotismo:

“El Ejército, necesidad permanente de las Naciones, responde a los más trascendentales objetos, lleva sobre sus banderas la consigna sagrada de defender la independencia y la integridad de la República, mantener el orden, sostener a las autoridades constituidas y proteger a las personas y los intereses, en los términos establecidos por la ley" (Ministerio de Guerra y Marina, 1882: 1-4).

Para sostener estas afirmaciones, Roca no remitía ya al ejemplo de los Estados Unidos, que había sido central para las iniciativas militares durante la presidencia de Sarmiento, sino a los ejércitos europeos. Las comisiones que se ocuparon de los proyectos de reforma se inspiraron en la situación del viejo continente, e incluso en 1881 jefes y oficiales del Ejército fueron enviados a Europa para recabar la información necesaria para avanzar en esa dirección. Esto no significa que la legislación estadounidense, que durante tanto tiempo había dado argumentos a los anticentralistas en materia militar, dejara de ser discutida. Por el contrario, por gestiones de Miguel Navarro Viola, el propio Ministerio de Guerra promovió la publicación de la normativa vigente sobre las fuerzas armadas de los Estados Unidos. Probablemente lo hizo para socavar argumentos a favor de la diseminación del poder militar, mostrando que incluso en ese país se estaba revirtiendo la tendencia descentralizadora que había prevalecido hasta la Guerra de Secesión (Ministerio de Guerra y Marina, 1881). ${ }^{33}$

En esa iniciativa de ley, que debía ser tratada por una comisión especial antes de ser enviada al Congreso, el presidente señaló que el nuevo Ejército nacional, tanto en su vertiente de Línea como la Guardia Nacional, debía además estar sujeto a reglamentaciones más severas que impidieran sublevaciones y uso de las armas con otros fines que los que el presidente consignaba. Agregó, también, que para terminar de construir un ejército realmente nacional, se debía garantizar por primera vez el servicio obligatorio de todos los ciudadanos. ${ }^{34}$ En la comisión espe- 
cial para la redacción de esta normativa Roca nombró al ex ministro de Guerra, Carlos Pellegrini, al Director del Colegio Militar, Simón A. de Santa Cruz, ${ }^{35}$ y al diputado Rafael Ruiz de los Llanos, originario de Salta, pero entonces elegido por Buenos Aires, quien había sido compañero de Roca en el Colegio de Concepción del Uruguay y con quien tenía una relación muy cercana. Esa comisión presentó un extenso proyecto que dividía al Ejército Nacional en Ejército regular, reserva del Ejército regular, Guardia Nacional activa y Guardia Nacional pasiva para hacer frente a potenciales conflictos exteriores. ${ }^{36}$ En sintonía con las preocupaciones del presidente, buscaba hacer efectiva la conscripción de todos los ciudadanos de 20 a 40 años y establecer en la práctica por primera vez el sistema de sorteo de quiénes, entre ellos, debían formar parte activa del ejército regular por tres años (Ministerio de Guerra y Marina, 1882: 7-9). Al mismo tiempo, la comisión reducía al mínimo las estipulaciones, con la convicción de que "debe dejarse una amplia parte a la reglamentación del Poder Ejecutivo”, buscando acentuar así la concentración del manejo militar en ese poder.

La gestión del PAN nacía entonces persiguiendo una centralización y concentración del poder coactivo: en el Gobierno nacional frente a las provincias, en el Ejecutivo frente al Legislativo. ${ }^{37}$ Pero también, apuntando un diseño militar novedoso, preocupado por las relaciones exteriores, que atendía antecedentes más allá del modelo norteamericano y redefinía el papel del reclutamiento y de las milicias ciudadanas. Esa iniciativa presidencial fue apuntalada descle el Ejército Argentino. Semanario del Ejército, Armada y Guardia Nacional de la República Argentina, que apareció en esos años como órgano oficial de las fuerzas militares. ${ }^{38}$ Esta publicación, editada por la Comandancia General de Armas como "la expresión de los sentimientos y de las aspiraciones de nuestra clase militar", ${ }^{39}$ no resultaba una iniciativa aislada. En esos años se fundaron otros espacios de sociabilidad y publicidad, como la Revista Militar y Naval, publicada mensualmente desde 1880 por el Ministerio de Guerra, el Círculo Militar, creado en 1881, y el Centro Naval, establecido en 1882, que publicó su propio Boletín. Estas instituciones y órganos de prensa buscaban congregar a los hombres de armas que para entonces habían pasado por nuevas experiencias formativas y aglutinadoras, como las campañas contra las poblaciones indígenas de Patagonia y Chaco, y llegar también a quienes formaban parte de las primeras generaciones de egresados

pero revolucionaria como ninguna". Lucio V. Mansilla, Del Ejército Argentino y bases para el establecimiento de una Escuela Militar Nacional, Buenos Aires, El Nacional, 1863, p. 3 citado en Dick (2014: 39).

35 En 1880 se eliminó la figura del cadete -formado por la práctica y no sistemáticamente-y se esperaba pronto eliminar a los distinguidos (voluntarios que también carecían de instrucción sistemática), para que las plazas fueran ocupadas por aspirantes a oficiales del Colegio Militar (Codesido, 2016: 266).

36 En las especificaciones se detallaba que todos los ciudadanos de entre 20 y 40 años debían formar parte del Ejército regular por tres años, y de la reserva de este por otros seis. Y que quienes tuvieran entre 20 y 29 años y no hubieran sido designados para el Ejército regular o su reserva, formarían parte de la Guardia Nacional activa y de la pasiva aquellos entre 29 y 40.

37 El proyecto estipulaba además que el Ejecutivo Nacional, no el Congreso, estaría facultado para reglamentar la disciplina de la Guardia Nacional de la Capital y los territorios nacionales (Ministerio de Guerra y Marina, 1881: 98-99).

38 Aparecía los sábados a la mañana con una extensión aproximada de 16 páginas y un tiraje en un principio de 2.500 ejemplares que luego ascendió a 3.000 .

39 (10 de Noviembre de 1883), Ejército Argentino, núm. 11, p. 318. La cita corresponde a una nota del editor sin firma. 
del Colegio Militar. Constituían, de ese modo, intentos por materializar la idea tan claramente postulada por la publicación de la Comandancia de que existía una "clase militar" que, lejos de resultar un antecedente de estas iniciativas, fue más bien su resultado, al otorgarles a esos hombres una voz colectiva y espacios de socialización más vastos. ${ }^{40}$

A través de esas experiencias, ese actor en formación comenzó a adquirir contornos más definidos que en el pasado y buscó intervenir en las discusiones entre el Ejecutivo y el Congreso relativas a la organización de las tres armas (todavía desde fuera del recinto, a diferencia de la década siguiente). En efecto, ese espíritu asociativo y las nuevas publicaciones especializadas habían nacido de la fría recepción que había tenido el proyecto elaborado por el Ejecutivo sobre reclutamiento del Ejército y enrolamiento de la Guardia Nacional. Presentado al Congreso en julio de 1881, no tuvo tratamiento legislativo ni ese año ni los siguientes. ${ }^{41} \mathrm{El}$ semanario buscó explicar esa indiferencia del Poder Legislativo frente a la cuestión militar en función de la falta de militares en el Congreso y tomó como bandera la defensa de dicha iniciativa. ${ }^{42}$ La difusión y promoción del proyecto tuvo, además, otros canales que fueron más allá del Ministerio. Por ejemplo, el Club Naval y Militar organizó en febrero de 1884 una conferencia, que fue publicada a continuación como folleto, y en la que se abordaban las fallas de la legislación vigente en materia de reclutamiento del ejército y enrolamiento de la guardia nacional. Especialmente el que en la práctica el Ejército terminara siendo constituido por destinados, "hombres perjudiciales a la sociedad [...] ladrones, asesinos, heridores, jugadores y todo lo malo", pues nunca se había puesto en práctica el sistema de sorteo de contingentes de guardias nacionales para contribuir a su remonta sancionado durante la presidencia de Sarmiento. El autor encontraba en esas fallas las razones de alzamientos y motines militares que habían caracterizado la historia nacional, y estudiaba el sistema servicio obligatorio tal y como se practicaba en algunos Estados europeos para proponer un sistema de ese tipo para la Argentina (Díaz, 1884: 26). A su juicio, y como también proponía el Ejecutivo -cuyo proyecto la conferencia reproducía-, a través del enrolamiento compulsivo de los hombres de 19 años y el sorteo de quienes debían integrarse al Ejército se aplicaría finalmente en la esfera militar el principio republicano de igualdad ante la ley. Sobre el final, el autor planteaba algunas diferencias con la propuesta que debía tratarse en el Congreso "hoy, que es de esperarse se ocupe de este proyecto", y llamaba a los legisladores a tenerlas en cuenta a la hora de discutirla, para que "llegue al Parlamento Argentino donde tenemos tan poca representación, la opinión de un soldado" (Díaz, 1884: 40; 49). ${ }^{43}$

40 Véase, especialmente: (22 de Septiembre de 1883 ), La unión es la fuerza, Ejército Argentino, núm. 4, pp. 103-4. Firmada por Alberto Capdevilla. Capdevilla había tenido una destacada actuación militar contra la insurrección de 1880, y posteriormente durante esa década fue Jefe de la Oficina de Enganche de Río Cuarto, Director de la Escuela de Cabos y Sargentos y Jefe de Policía de la Capital.

41 Tampoco habían tenido mucho eco en la prensa, salvo en el oficialista La Tribuna Nacional, que se limitó a reproducir el proyecto en su número del 21 de julio de 1881.

42 (15 de Septiembre 1883). Ejército Argentino, núm. 3. También: el número 18, publicado el 29 de diciembre de 1883, p. 539.

43 Para las opiniones en contra de un reclutamiento compulsivo aparecidas en esos años en la Revista Militar, véase Avellaneda (2017: 134-136). 
Pero el Congreso eludió esa discusión. Según dejaba entender Alberto Capdevilla en el semanario oficial, ${ }^{44}$ los legisladores que apoyaban al presidente ni siquiera iniciaban el tratamiento del proyecto, a sabiendas de las controversias que traería en las Cámaras por motivos previsiblemente similares a los que había desatado la ley 1.072 sancionada en 1880: que cualquier reforma en esa materia alteraba simultáneamente la relación nación-provincias, las respectivas prerrogativas del Ejecutivo y Legislativo en materia militar, y los derechos políticos de los soldados-milicianos. Los legisladores del PAN aplazaban la cuestión porque no querían dejar al Poder Ejecutivo (entonces en manos de Roca, quien se había proyectado a la presidencia de la Nación precisamente descle la cartera de Guerra) en la incómoda situación de ver un proyecto de ley militar rechazado por las Cámaras, donde su partido tenía una cómoda posición..$^{45} \mathrm{El}$ semanario señalaba, además, una falla más estructural en las relaciones entre el Congreso y el Ejército: el temor que advertía entre los legisladores a lo que denominaba "militarismo", a que la "clase militar" se erigiera en una amenaza para la plena vigencia de los derechos políticos. ${ }^{46}$ En sintonía con esas preocupaciones, se lamentaba de que el Ministerio de Guerra hubiera sido desempeñado en el pasado por políticos y no por hombres que fueran "parte íntima del ejército o de la armada", y celebraba que esa tendencia se estuviera revirtiendo bajo la presidencia de Roca con la designación del Coronel Benjamín Victorica en esa cartera, aunque todavía hubiera tantos escollos en el Congreso.

Victorica instó infructuosamente al Congreso en otras oportunidades a que avanzara en la reglamentación militar para terminar con la labor discrecional de las provincias en esa materia y preparar el terreno para "el servicio obligatorio" (Argentina, 1883: 27). Sobre el fin de su presidencia, Roca insistió sin éxito a las Cámaras para que sancionaran la ley de reclutamiento del Ejército y enrolamiento de la Guardia Nacional. Y su sucesor, Miguel Juárez Celman, en vistas del pantano en que se hallaban los proyectos militares, debió retirarlos en 1886, para "hacer un estudio de ellos, en el sentido de armonizar estas leyes a los adelantos de estas materias en el tiempo transcurrido" (Argentina, 1887:69). Junto con su ministro de Guerra, Eduardo Racedo, enviaron por última vez al Congreso un proyecto de organización del Ejército nacional en agosto de 1889, para "[distribuir] equitativamente el servicio militar que todos los ciudadanos están obligados a prestar en defensa de la Nación" (Argentina, 1889:528). Una de las cuestiones más espinosas que traía esta nueva propuesta era la explicitación de que el Ejecutivo Nacional tendría la facultad de designar jefes y oficiales una vez que la Guardia estuviera movilizada (en la etapa previa a la movilización esa designación dependería, como lo había sido hasta ese momento, de los gobernadores). El proyecto pasó a la comisión de Guerra, pero no recibió tratamiento hasta la caída del gobierno de Juárez al año siguiente (Quinterno, 2014:114-7).

44 (22 de septiembre de 1883), Ejército Argentino, núm. 4, p. 103.

45 Véase además en (22 de septiembre de 1883), Ejército Argentino, núm. 4, p. 77, la nota "Venga en buena hora la reforma", firmada por Francisco Reynolds, Teniente Coronel de Artillería y Secretario de la Comisión Inpectora del Colegio Militar.

46 (22 de septiembre de 1883), Cuidemos, un poco, el estómago del Ejército, Ejército Argentino, núm. 4, pp. 73-74. Editorial sin firma. 
¿Por qué el Congreso se negó reiteradamente a tratar esos proyectos? Es difícil dar una respuesta concluyente, en la medida en que efectivamente nunca llegaron a tener tratamiento parlamentario, por lo cual los legisladores no debieron expedirse de manera explícita. Sin embargo, hay algunas pistas en los documentos de época. En principio, el fracaso de las iniciativas no nació de diferencias partidarias, pues el partido gobernante tenía mayoría en las dos Cámaras. En función de lo expuesto en las memorias ministeriales y en la prensa oficial del Ministerio, las causas radicaban más bien en un conjunto de fallas que los legisladores encontraban en ellos: que traerían una expansión del poder de esa "clase militar" que les suscitaba temores; que fijarían nuevas relaciones en materia militar entre nación-provincias (en lo que había predominado una concurrencia de jurisdicciones de hecho que el derecho podía alterar); y finalmente que expandir el manejo efectivo que tenía el presidente -como comandante en jefe del Ejército-sobre los cuerpos de reserva con sede en las provincias aumentaba los poderes de guerra del titular del Ejecutivo y recortaba el margen de regulación que el Congreso buscaba conservar en materia militar.

\section{Las políticas de reclutamiento e instrucción de los milicianos y sus efectos en los conflictos armados}

Durante esa primera década de dominio del PAN no desaparecieron los conflictos armados, aunque resultaron menos frecuentes que en el pasado. Por una parte, porque las oposiciones al partido habían quedado muy debilitadas tras su derrota en el conflicto de 1880. Por otra, porque el PAN procuró tramitar sus disputas internas por la vía de la negociación (Alonso, 2010). Con todo, es importante observar las características de los episodios armados que tuvieron lugar, para ponderar cuál fue el alcance de los intentos de ese partido de socavar las bases materiales que hacían posible esos alzamientos, a través de una centralización de las fuerzas militares y de la puesta de las milicias ciudadanas bajo el comando profesional. Lo que se observa en este punto, como presento a continuación, es que las luchas armadas de esos años no obedecieron necesariamente a la negativa del Congreso a aprobar los proyectos normativos impulsados por el Ejecutivo, como este sugirió en los debates del ochenta. Fueron también producto, indirecto y no deseado, de medidas tomadas el propio Poder Ejecutivo en el margen de maniobra que tenía para sortear una definición legislativa en lo relativo al reclutamiento y la instrucción de los soldados.

Como mencioné, a fines de 1880 Roca decretó la reorganización de la Guardia Nacional en todo el territorio del país. Si bien el presidente comisionaba a los gobernadores en lo relativo al reclutamiento, dictó inmediatamente otro decreto que estipulaba la creación de las Intendencias Generales del Ejército. Éstas dependerían del Ejecutivo Nacional y deberían llevar adelante la organización y movilización de las Guardias Nacionales en las provincias como Ejército de reserva, avanzando sobre facultades habitualmente desempeñadas por los gobernadores (Argentina, 1896: 347; Codesido, 2016:342). Los subinspectores debían ser jefes del 
Ejército de Línea, que constituirían el Comando en Jefe de la Guardia Nacional; es decir, aunque los reservistas fueran ciudadanos-milicianos, los comandantes serían militares de carrera o profesionales "teniendo en consideración (...) la importancia de someter desde el primer momento la Guardia Nacional, una vez que fuese movilizada en servicio de la Nación, al mando militar para su mejor disciplina, aprovisionamiento, armamento y equipo". ${ }^{47}$

Esta medida era propuesta en el marco de una transformación mayor en la instrucción militar de los milicianos, que era promovida desde la Comandancia de Armas. ${ }^{48}$ Ejército Argentino abogaba por que, hasta tanto se sancionara la ley de servicio militar compulsivo, la Guardia Nacional realizara sus ejercicios doctrinales no en domingos y días de fiestas como lo hacía hasta ese momento, sino en el cuartel. ${ }^{49}$ De ese modo, se construiría una "escuela militar obligatoria por la que todo ciudadano pasa..., lo cual consideraba que tendría un efecto decisivo en la transformación de la sociedad: "Durante ese periodo, la edad social más peligrosa para la juventud, se le fortalece material y moralmente y se le separa de la vorágine social ... la milicia cimentada bajo estas bases, será una escuela superior de moralidad y de instrucción.... ${ }^{50}$ La publicación de la Comandancia fijaba también que hasta tanto se pudieran garantizar condiciones de salubridad e higiene en los cuarteles del ejército de Línea, los guardias nacionales deberían de manera transitoria ejercitarse en "un depósito de reclutas en los suburbios de los pueblos, cabeza de circunscripciones militares, para irlos habituando a las intemperies y fatigas de la carrera". ${ }^{1}$

Aunque el texto no lo mencionaba, con el sistema de cuarteles (su versión preliminar de depósito de reclutas y el ideal futuro de campos permanentes de instrucción o campamentos cuarteles como mostraba el ejemplo de Europa Occidental $)^{52}$ se podría cortar el lazo que durante las décadas previas había unido al miliciano con su localidad y con las diputas políticas que la atravesaban. En ese sentido debe entenderse la meta planteada por el semanario de transformar el espíritu guerrero del argentino en un espíritu militar disciplinado:

En la tristemente larga serie de guerras que hemos sostenido desde nuestra emancipación política, la población viril desde la edad tierna del educando de primer grado hasta la achacosa de la existencia, se ha acostumbrado a calzar la espuela y ajitar un sable o manejar un arma de fuego. El espíritu guerrero así infiltrado en el organismo argentino, ha operado hazañas [...] Pero, el espíritu guerrero no es el espíritu militar,

47 En el caso de la provincia de Buenos Aires, directamente se la puso bajo la jurisdicción de la Comandancia General de Armas (Argentina, 1896: 347). La designación de soldados profesionales al mando de las guardias nacionales era una de las claves para subordinar a estas fuerzas al mando nacional.

48 En 1883 Victorica informó al Congreso que el PEN iba a presentar un proyecto de ley de organización y disciplina de la Guardia Nacional en toda la República para suplir la vacancia de la ley que la Constitución había encargado al Legislativo y que el Congreso no había hecho hasta el momento (Argentina, 1883: 27).

49 (6 de octubre de 1883 ), Ejercicios doctrinales de la guardia nacional, Ejército Argentino, núm. 6, pp. 144-5. Firmada por Pedro Mallo, Cirujano Mayor que encabezaba el Cuerpo de Sanidad de la Armada.

50 (3 de noviembre de 1883), Modificaciones físicas e intelectuales en la vida militar, Ejército Argentino, núm. 10, p. 295. Firmada también por Mallo.

51 Idem, p. 296

52 (17 de noviembre de 1883), Ejército Argentino, núm. 12, p. 345. Sin firma. 
producto de una educación sistemática, que principiando en la escuela graduada se completa en el ejército, que es la escuela de aplicación, vive siempre patente en las filas del pueblo y resalta en las aspiraciones de la opinión pública.

Para lograr esa transformación, el semanario exhortaba a los ministros de guerra e instrucción pública a ir un paso más allá e incorporar a las escuelas, junto con la educación cívica centrada en el estudio de la Constitución, clases de gimnasia e instrucción militar, que "consiste en los movimientos tácticos más usuales, manejo de fusil y su esgrima y ejercicios corporales metódicamente repartidos, a fin de fortalecer el espíritu desarrollando y vigorizando los músculos del cuerpo". ${ }^{53}$ Este mensaje del semanario no desentonaba con su contexto. El propio Ministerio de Guerra había informado que la dirección de Infantería del Ejército estaba evaluando un tipo de fusil Remington, modelo del Ejército Argentino, que sería entregado a todos los Colegios Nacionales, para que se impartiera instrucción militar en los establecimientos. ${ }^{54}$

Todas estas iniciativas apuntaban a colocar a los soldados-milicianos no profesionales de los los distritos provinciales bajo la administración e instrucción del ejército profesional. Pero se vieron permanentemente frustradas porque no lograban resolverse en la práctica las cuestiones operativas que resultaban una precondición para cualquier innovación: qué autoridades civiles y militares estarían a cargo de tales transformaciones. Incluso en las cuestiones en que el Ministerio y el presidente no necesitaban en principio la cooperación del Legislativo, como en llevar adelante el reclutamiento en el marco de la legislación vigente, se produjeron idas y vueltas, maniobras contradictorias y cambios abruptos que complicaron la organización militar. La acción del nuevo Estado nacional, que en general la historiografía ha considerado como consolidado en $1880,{ }^{55}$ encontraba varias limitaciones prácticas para asegurar su predominio en materia militar (como en varios otros aspectos) y su accionar fue por ello vacilante, por momentos se sucedieron medidas incoherentes entre sí, y no siguió de ningún modo un curso unificado ni decidido.

Un ejemplo de esa dinámica lo brindan las sucesivas medidas diseñadas y ejecutadas en esos años para la remonta del Ejército: Roca mandó a cesar a poco de andar las comisiones militares de Sub-Inspectores y estableció una Oficina de Enganche en cada provincia para llevar a cabo el reclutamiento con una dotación de un jefe, dos oficiales subalternos y tres ordenanzas del Ejército de Línea (Domínguez, 1898: Tomo 3, 35). Esas oficinas, que contaban con armas para 50 a 200 hombres (en función de las necesidades de cada provincia), constituían una presa deseada para quienes buscaban organizar insurrecciones. Por ese motivo, este instrumento también fue descartado el 27 de enero de 1887 y se dispuso que la remonta fuera hecha directamente por los cuerpos del Ejército y que el

53 (17 de noviembre de 1883), La educación militar en las escuelas civiles argentinas, Ejército Argentino, núm. 12, p. 334.

54 Sobre el peso que estos debates adquirieron en la década siguiente: Bertoni (2007).

55 Especialmente: Oszlak (1982). Una mirada atenta a las dificultades en la consolidación del estado nacional en los años ochenta en Gerchunoff, Rocchi y Rossi (2007). 
enrolamiento de la Guardia siguiera en manos de los gobiernos de provincia (Domínguez, 1898: Tomo 3, 210 y 236).

El presidente Juárez Celman también emitió un decreto en 1887 para terminar de reglamentar la Ley de reclutamiento de 1872, a través de la organización del jurado y las formas en que debía ejecutarse el sorteo de los Guardias Nacionales de cada provincia que tenían que concurrir a la remonta del Ejército (Domínguez, 1898: Tomo 3, 225-7). Al estar pendiente esa reglamentación, se había optado durante décadas por reclutar más destinados y mantener en servicio por más tiempo a voluntarios y enganchados pagándoles doble sueldo, lo cual significaba un peso considerable para el presupuesto de esa cartera (Argentina, 1881b:XV). ${ }^{56}$ En 1888 fue realizado el primer sorteo con muy malos resultados ${ }^{57}$ y a continuación el Ejecutivo dictó un nuevo decreto en el cual se disponía el envío de jefes del Ejército de Línea a cada una de las provincias para "presidir el sorteo, recibir los contingentes y remitirlos según las instrucciones que para ello se dictarán por el Estado Mayor" (Domínguez, 1898: Tomo 3, 279). A su vez, ese mismo año se resolvió en acuerdo general de ministros una completa reorganización de la Guardia Nacional, que debía empezar a regir el 1º de enero de 1889, “a fin de dar una forma definitiva de organización Militar eventual a la Guardia Nacional de la República”, articulando las guardias nacionales de las provincias con distintos cuerpos del ejército de Línea (Domínguez, 1898: Tomo 3, 269-72). Esta norma buscaba avanzar en la centralización y profesionalización de los milicianos hasta que el Congreso se dispusiera finalmente a sancionar proyectos de leyes orgánicas de organización de los ejércitos de la república. Pero no parece haber sido aplicada.

El Gobierno intentó también pautar algunos aspectos relativos a la organización interna del Ejército que apuntaban a centralizar su mando. En esos años, la comandancia se quejaba de la falta de un estado mayor que pudiera ordenar y dirigir a las fuerzas militares: "No tenemos hoy estado mayor, la Comandancia es una simple oficina de trasmisión; las Inspecciones, tan solo juris de consulta y es así que las demás reparticiones del ejército, miembros de un cuerpo viril sin cabeza organizada, marchan a la ventura aunque con facilidad, en la evolución complicada y científica del progreso de la guerra". ${ }^{58}$ Por ese motivo, el proyecto de organización del Estado Mayor General (EMG), sancionado a comienzos de 1884, se proponía erigir "ese gran centro [desde donde] se difunde a todo el Ejército las reglas de su régimen, de su disciplina, de su organización, las órdenes para sus operaciones". Esa iniciativa nacía tanto del reconocimiento de varias falencias relativas a la organización castrense, como de la necesidad de contar con

56 Hubo pedidos recurrentes por parte del Ministerio para que se aplicara el sorteo dispuesto por la ley de 1872 como solución transitoria hasta que se aprobara el servicio compulsivo de todos los ciudadanos. Argentina (1884:18-19); Argentina (1887: III y IV).

57 Sobre esta experiencia, Moroni y Espinosa Fernádez, 2007; Quinterno, 2014: 116; Avellaneda, $2017 \mathrm{~b}$ y 2019. En su tesis defendida en la Universidad de Buenos Aires, el nieto de Victorica sintetizaba las razones del fracaso en la mala voluntad de las autoridades de provincia para aplicar el sorteo (García Victorica, 1911: 97).

58 (8 de septiembre de 1883). Proyecto de ley creando un Cuerpo de Estado Mayor, Ejército Argentino, núm. 2. Firmado por el Coronel Álvaro Barros, un militar con extensa trayectoria en el ejército y con actuación política y periodística, que se había destacado por sus publicaciones sobre el problema de la frontera interna. Había sido gobernador de Buenos Aires y de la Gobernación de la Patagonia. 
un interlocutor entre las fuerzas militares y los legisladores para avanzar en la reglamentación de los mencionados mecanismos de reclutamiento e instrucción. ${ }^{59}$

Pero los resultados inmediatos de la centralización en el EMG no fueron muy promisorios. No logró revertir las cambiantes y frustradas medidas en materia de remonta del Ejército en las provincias, que estuvieron lejos de contribuir a la tan ansiada pacificación de la política promovida por los hombres nucleados en el PAN. En esos años tanto las oficinas de enganche del Ejército, como los propios batallones del Ejército de Línea y los cuerpos de milicias que seguían funcionando en las provincias resultaron elementos de perturbación. Durante 1883, la oficina de enganche de Santiago del Estero se involucró en un conflicto por la sucesión en la gobernación (Sommariva, 1931: Tomo 2,114-5). Al año siguiente se produjo en Catamarca un enfrentamiento armado en el que participaron milicianos comandados por un cura y oficiales del enganche. Esos alzamientos pusieron nuevamente en debate si el Ejército de Línea debía intervenir en esos enfrentamientos que tenían lugar en las provincias o si correspondía a éstas mantener el orden en sus territorios. Incluso en una cuestión medular como esta, hubo diferentes posturas dentro del gobierno. Victorica se inclinó por mantener la jurisdicción provincial, mientras que el ministro Francisco J. Ortiz (que estuvo a cargo de la cartera interinamente en 1885) y luego Carlos Pellegrini la combatieron, al considerar que encargar a los gobernadores sostener la represión en sus territorios solo contribuía a atizar los conflictos en las provincias (Sommariva, 1931: Tomo 2, 131-2).

A pesar de que Juárez Celman había suspendido a comienzos de 1887 las Oficinas de Enganche para evitar futuros disturbios, por algunos meses siguieron funcionando en algunas provincias, como fue el caso de Tucumán. Allí, esa oficina dio protección a un individuo que estaba siendo perseguido por el jefe de policía, lo cual derivó en un enfrentamiento armado entre empleados nacionales procedentes de Córdoba, y provistos de armas del Ejército, que combatieron al gobernador y a la Guardia Provincial. Tampoco fue exitoso el cumplimiento de la disolución de cuerpos militares en las provincias, que siguieron funcionando al menos en Buenos Aires, Santiago del Estero, Santa Fe y Corrientes. ${ }^{60}$ En esta última, el Inspector de Milicias acuarteló en 1885 a sus soldados contra el gobernador, haciéndolo renunciar. Inmediatamente, el presidente Roca ordenó disolver ese batallón, que resultaba ilegal, y esa medida causó revuelo en las Cámaras, a pesar de ser una ley que ese mismo Congreso había aprobado apenas cinco años antes. Por último, en 1889 estalló un conflicto armado en Mendoza cuando un regimiento del propio Ejército de Línea se alzó contra el gobernador. Ese episodio inauguró una crisis política dentro del partido gobernante, que se profundizó por las dificultades económicas que atravesaba la Argentina en ese momento y alentó la organización en Buenos Aires del movimiento armado que terminó con la presidencia de Juárez Celman en 1890 (Sommariva, 1931: tomo 2, 124-154).

59 Sobre la importancia de la creación del EMG, véase Comando en Jefe del Ejército (1971: 34-6), de donde está tomada la cita. También se crearon la Escuela de Cabos y Sargentos (1884) y la Escuela de Ingeniería Militar (1886), la Escuela Normal de Tiro (1887), y en 1885 se terminó de reglamentar la Ley de Ascensos sancionada en 1882 y que fue utilizada extensamente en esos años para promover a jefes, oficiales y oficiales subalternos (Domínguez, 1898: tomo 3, 162-3).

60 “Informe del Ministro de Guerra y Marina” (Argentina, 1886: 267). 
¿Qué nos dicen esos episodios sobre los alcances de largo plazo de la política militar? En primer lugar, muestran las dificultades y vacilaciones del Gobierno nacional en hacer cumplir las leyes del Congreso. En la interpelación del ministro interino de Guerra, Francisco Ortiz, en 1885, éste sostuvo que, aunque el Poder Ejecutivo conocía de manera extraoficial que varias provincias mantenían cuerpos militares organizados contra la ley sancionada en 1880,

\begin{abstract}
ha creído que no ha llegado el momento ni que es conveniente, ni político, ni prudente hacerla, ni decretar la disolución de esos cuerpos, desde que, por el momento, ellos no ofrecen ningún peligro a la tranquilidad pública ni son un obstáculo para el ejercicio tranquilo de las instituciones. El gobierno considera que la ley relativa a la disolución de estos cuerpos militares, debe, en su aplicación, ser estrictamente dirigida por las circunstancias del momento (...). El objeto, el espíritu de esa ley cuando se dictó, ha sido evitar que la anarquía parta de las provincias contra el gobierno nacional, que el orden público se altere. Así es que, mientras el Poder ejecutivo tenga la seguridad de que ese orden no está amenazado por esas fuerzas que existen en algunas provincias, bajo tal o cual denominación, más o menos aproximada a la que la ley determina, y que no son un obstáculo para el ejercicio de las libertades públicas y de las garantías constitucionales, no es prudente, como he dicho, ni es político destruirlas u ordenar su disolución, a menos que una ley del Congreso especialmente determine lo contrario (Argentina, 1886: 267).
\end{abstract}

Salvo para los casos de Buenos Aires en 1880 y Corrientes en 1885 -precisamente las dos provincias que habían resistido el triunfo presidencial de Roca-, la Ley 1.072 era letra muerta no solo para muchos gobernadores, sino también para el propio Poder Ejecutivo Nacional, según se desprende del fragmento.

En segundo lugar, esos episodios muestran también que las Oficinas de Enganche y el despliegue de batallones de Línea en territorios provinciales -que el Gobierno nacional organizó y reorganizó constantemente-, más que desarmar la conexión en las provincias entre armas y política, tendieron a reforzarla. Es decir, que los levantamientos armados que no involucraron milicias locales, se organizaron sobre la base del Ejército de Línea en el cual el gobierno cifraba sus esperanzas en materia de despolitización y profesionalización militar.

En lo que hace a la Capital, las medidas que siguieron a los enfrentamientos del ochenta tampoco fueron exitosas para separar a las fuerzas militares de los conflictos partidarios. Para evitar la repetición de esos sucesos, se había reorganizado la Guardia Nacional de Buenos Aires, descabezado a sus batallones y nombrado nuevos comandantes, poniéndolos bajo estricto control del Poder Ejecutivo (primero bajo el imperio de la Comandancia General de Armas y luego del EMG). Esa previsión relativa a las milicias se mostró insuficiente para resolver el problema de base, pues en julio de 1890 sectores descontentos del Ejército se sumaron al alzamiento armado contra Juárez Celman (Comando en Jefe, 1971: 261; Alonso, 2010). Ese movimiento, que fue derrotado militarmente pero logró la renuncia presidencial, abrió otro capítulo en la dinámica de la política nacional y en los debates sobre la organización, instrucción y disciplina de las fuerzas militares. 


\section{Conclusiones}

El objetivo de este trabajo fue analizar los alcances y límites de las iniciativas gubernamentales que en los años ochenta buscaron crear un nuevo Ejército moderno y profesional. Para poder avanzar en esa profesionalización, los proyectos impulsados por los ministros de Guerra y por Roca y Juárez consideraron necesario asegurar el mando del Poder Ejecutivo Nacional tanto sobre el Ejército de Línea como sobre las guardias milicianas y, sobre esa base, promover la implantación de un sistema de servicio compulsivo de entrenamiento militar de todos ciudadanos bajo la comandancia de soldados profesionales.

Esas iniciativas no lograron los consensos necesarios. Sin duda, la situación de relativa paz de los años ochenta contribuyó a aplazar estas cuestiones. Pero del análisis aquí realizado se desprende que hubo otros factores que intervinieron en esas postergaciones y que hacían a las relaciones entre los poderes públicos, al problema federal y a la política partidaria. En ese sentido, las vicisitudes de esas iniciativas pueden iluminar algunas aristas de tres cuestiones históricas centrales de esa etapa que han estado en el foco de los especialistas: las controversias y definiciones en torno a la organización del estado y las relaciones entre nación y provincias; las relaciones respectivas entre los poderes públicos en materia de movilización y e instrucción de la tropa; y el funcionamiento efectivo de los variados batallones militares como espacios de incorporación y movilización política de amplios sectores de la población y, como tal, un nudo problemático que el PAN aspiraba a desarmar.

Esta exploración mostró que el mayor escollo en la política militar estribaba en que, para intentar siquiera ordenar y subordinar las distintas fuerzas militares al comando nacional, era necesario alterar las relaciones de hecho entre nación y provincias, en las que estas últimas intentaron mantener el status quo. Revisar esas dificultades que el Estado nacional tuvo para asegurar su predominio en materia militar tras su triunfo en 1880, puede entonces contribuir a repensar las cronologías de esas etapas de construcción y consolidación estatal.

El análisis precedente evidencia también que la vacilante política militar en los años ochenta no nacía solo de dificultades materiales y políticas para hacer cumplir las prescripciones en las provincias. Fue alimentada, asimismo, por los propios desacuerdos que tuvieron lugar en el partido gobernante sobre los límites de cada jurisdicción en el mantenimiento del orden y en la organización de los ejércitos de la República. En ese sentido, el análisis de las iniciativas y de los fracasos parlamentarios puede ofrecer elementos para comprender el funcionamiento de los poderes públicos, y en especial la dinámica de colaboración y confrontación entre el Congreso y el presidente durante los primeros años de dominio hegemónico del PAN. Esos desacuerdos políticos y doctrinarios fueron evidentes, por ejemplo, en las interpelaciones a los ministros de Guerra que se dieron a lo largo de esa década, que en definitiva alentaron la "indisciplina" de las provincias, cuyas dirigencias formaban, con todo, la columna vertebral del PAN. ${ }^{61}$ 
Merece destacarse que en los años ochenta ni el presidente y sus ministros ni los legisladores apelaron a grandes argumentos teóricos para defender sus facultades respectivas en materia militar, como había sido el caso en general de la tónica parlamentaria hasta los debates de 1880. Durante la llamada "organización nacional", quienes defendían la dispersión del poder habían puesto el acento en un argumento republicano y en uno federal: dar instrumentos a los ciudadanos para controlar el poder de los gobernantes y permitir que la doble jurisdicción militar sirviera como un contrapeso a una concentración desmedida del poder de fuego en el PEN. Mientras que quienes, como Sarmiento, buscaban centralizar el poder a nivel nacional y concentrarlo específicamente en el presidente, habían sostenido que tal unidad era necesaria para poder actuar con rapidez en todo el territorio frente a las recurrentes crisis en las provincias (Cucchi y Romero, 2017).

Esas dos dimensiones del problema militar aparecían algo modificadas en los años ochenta. Roca ciertamente buscaba una centralización, pero no basaba sus argumentos en una supuesta preeminencia de los poderes nacionales frente a los locales -tema por completo ausente en las iniciativas militares-, sino en la necesidad de establecer un comando central, moderno y profesional, de modo de asegurar la eficiencia necesaria para atender a potenciales conflictos exteriores. Asimismo, en su defensa de los proyectos no tenía ningún lugar la cuestión de los poderes de guerra del presidente, que había obsesionado a Sarmiento. Del lado opuesto, quienes objetaban ese nuevo diseño militar -si atendemos a las lecturas hechas al respecto por la comandancia de Armas- apelaron en general a dos razones. Primero, señalaron que un contexto en que las fuerzas Policía y Gendarmería no estaban plenamente desarrolladas, los gobiernos locales debían seguir apoyándose en la labor de ciudadanos-milicianos para garantizar las tareas de orden público. Segundo, temieron el desbalance en las atribuciones de los poderes públicos que podría traer una subordinación total de las milicias al ejército profesional (en detrimento del Congreso y a favor del PEN) y sobre todo que "la clase militar" fuera desarrollando así un poder desmedido e incluso independiente del presidente como Comandante en Jefe y se erigiera en un peligro para la vida republicana.

La aparición de esa "clase militar" aparece como un cambio significativo de esta década. Aunque las transformaciones normativas de esos años fueron más bien modestas, en simultáneo a esas discusiones se fue produciendo un desarrollo material e institucional del Ejército que comenzó a delinear una voz propia en estos debates. El aumento de esa presencia pública -que fue evidente en la década siguiente cuando el Ejército se hizo oír en el tratamiento y aprobación del sistema de reclutamiento compulsivo consagrado finalmente en 1901 por la ley Ricchieri- tiene en parte su origen en la organización durante los años aquí analizados de asociaciones militares y de prensa especializada, entre la que se destacó el propio semanario del Ejército. Esta publicación no solo articuló a la oficialidad como un actor institucional y público, sino que también resultó 
importante para el adoctrinamiento de sectores más amplios. ${ }^{62}$ Su prédica llegó a oficiales, suboficiales y tropa, constituyéndolo en un órgano clave de homogenización de las fuerzas militares en un momento en que estas estaban sufriendo varios cambios en su propia estructura y composición (con las primeras camadas de egresados del Colegio Militar), y funcionó además como una herramienta de difusión de instrucción militar y de los deberes del soldado entre las tres fuerzas. Con ese objetivo en vista, el semanario fue enfático en el tono simple y concreto que debían tener sus artículos, para que pudieran ser leídos y comprendido hasta por el "último soldado". ${ }^{63}$

Por último, los límites que encontraron en los años ochenta las iniciativas de centralización militar no solo frenaban los intentos de profesionalización de las fuerzas, sino que traían también problemas adicionales al partido gobernante, en la medida en que la diseminación efectiva del poder militar socavaba cualquier intento de pacificación política que constituía en núcleo de su programa de gobierno. Por ese motivo, el análisis de los alcances de sus iniciativas permite también volver sobre la dinámica política de esos años y pensar las condiciones de posibilidad de los alzamientos que se produjeron en ese momento en algunas provincias, y tal vez también de aquellos que tuvieron lugar en la década siguiente, en el marco de la expansión de la actividad opositora que caracterizó a los tempranos años noventa.

62 Según indicaba, su prédica llegaba a las "todo el ejército, armada y guardia nacional, con ramificaciones en las escuelas, fábricas, hospitales y en todas las clases sociales, a fin de que la publicación no fuese el eco de una o dos personas, sino el portavoz de las necesidades e intereses de la milicia argentina." (1883), Ejército Argentino, p. 101. El semanario recibía correspondencia de comandantes que le informaban que lo distribuían entre la tropa. Véanse: núm. 5, del 29 de septiembre de 1883, p. 130; y núm. 6, del 6 de octubre de 1883, p. 162.

63 (20 octubre de 1883). Ejército Argentino, núm. 8, p. 231. 


\section{Q Bibliografía}

"Alonso, P. (1997). 'En la primavera de la historia'. El discurso político del roquismo de los años ochenta a través de su prensa. Boletín de Historia Argentina y Americana Dr. Emilio Ravignani, 15, pp. 35-70.

" Alonso, P. (2010). Jardines secretos, legitimaciones públicas: El Partido Autonomista Nacional y la política argentina de fines del siglo XIX. Buenos Aires: Edhasa.

" Argentina (1879). Cámara de Senadores. Sesión de 1879. Buenos Aires: El Nacional.

" Argentina (1879b). Diario de Sesiones de la Cámara de Diputados. 1879. Buenos Aires: La República.

" Argentina (1880). Cámara de Senadores. Sesión de 1880. Buenos Aires: El Nacional.

" Argentina (1881). Diario de Sesiones de la Cámara de Diputados. 1880. Buenos Aires: La República.

" Argentina (1881b). Memoria del Ministerio de Guerra y Marina presentada al Congreso por el ministro de guerra y marina Dr. D. Benjamín Victorica. Tomo I. Buenos Aires: La Pampa.

" Argentina (1883). Memoria del Ministerio de Guerra y Marina presentada al Congreso por el ministro de guerra y marina Dr. D. Benjamín Victorica en 1883. Buenos Aires: La Pampa.

" Argentina (1886). Diario de Sesiones de la Cámara de Diputados, 1885. Buenos Aires: Moreno y Núñez.

"Argentina (1884). Memoria del Ministerio de Guerra y Marina presentada al Congreso de 1884 por el ministro General Dr. D. Benjamín Victorica. Buenos Aires: La Pampa, 3 vols.

" Argentina (1887). El doctor D. Miguel Juárez Celman, presidente de la república, en el primer año de su gobierno, octubre 1886-1887. Buenos Aires: La Patria.

" Argentina (1889). Diario de Sesiones de la Cámara de Diputados, 1889. Buenos Aires: Compañía Sud-Americana de Billetes de Banco.

" Argentina (1896). Registro Nacional de la República Argentina. Tomo Octavo. 1878 a 1881. Buenos Aires: Penitenciaría Nacional.

" Avellaneda, A. (2017). Racionalidad militar e ingreso voluntario al Ejército a fines del siglo XIX. Ideas, sueños e hipótesis de una batalla perdida. Estudios Sociales del Estado, 3 (6), pp. 124-156.

"Avellaneda, A. (2017b.). El ciudadano de las barracas. Genealogía del servicio militar como problema y preocupación en los cuadros miliares argentinos en la esquina de los siglos XIX y XX. Coordenadas, IV (1), pp. 57-86.

"Avellaneda, A. (2019). Mundo militar y gobierno a distancia. Redes para el enrolamiento y sorteo militar de los jóvenes entre 1880 y 1910 en Argentina. Pasado Abierto, 10, pp. 204-241.

" Bertoni, L. A. (2007). Patriotas, cosmopolitas y nacionalistas. La construcción de la nacionalidad argentina a fines del siglo XIX. Buenos Aires: Fondo de Cultura Económica.

" Bohoslavsky, E. y G. Soprano (eds.) (2010). Un Estado con rostro humano. Funcionarios e instituciones estatales en Argentina (desde 1880 hasta la actualidad). Buenos Aires: Prometeo- UNGS.

" Botana, N. (1977). El orden conservador. La política argentina entre 1880 y 1916. Buenos 
Aires: Sudamericana.

"Botana, N. (1993). El federalismo liberal en Argentina: 1852-1930. En Carmagnani, M. (coord.). Federalismos latinoamericanos: México, Brasil Argentina. México: Fondo de Cultura Económica.

" Botana, N. y E. Gallo (1997). De la república posible a la república verdadera. Buenos Aires: Ariel.

" Bragoni, B. (2010). Milicias, Ejército y construcción del orden liberal en la Argentina del siglo XIX. En AA.VV., La construcción de la Nación Argentina. El rol de las Fuerzas Armadas. Buenos Aires: Ministerio de Defensa de la Nación.

" Canciani, L. (2012). Las Guardias Nacionales en Argentina durante la organización nacional: balances y perspectivas historiográficas. História. Unisinos, 16 (3), pp. 39-402.

"Canciani, L. (2019). Entre la ley y la práctica. La intervención de los comandantes de Guardia Nacional en los procesos electorales (provincia de Buenos Aires, 1876-1900). Trabajos y Comunicaciones, 49, s/d.

"Codesido, L. (2014). Militarización de la política y política de guerra en el Ejército argentino (1870). Faccionalismo, lealtades políticas y mecanismos de promoción de los jefes y oficiales durante el proceso de construcción del Estado. Historia Caribe, 24 (11), pp. 131-161.

"Codesido, L. (2016). La Nacionalización de las fuerzas armadas en la Argentina y su vinculación con el proceso de construcción del Estado argentino entre 1862 y 1880 . Tesis de Doctorado inédita, Universidad Nacional de La Plata.

" Comando en Jefe del Ejército (1971). Reseña orgánica e histórica el Ejército Argentino. Tomo 2. Buenos Aires: Círculo Militar.

" Cucchi, L. y A. L. Romero (2017). Tensions between Congress and the Executive in 19th Century Argentina: Federal Intervention and Separation of Powers. Parliaments, Estates and Representation, 37 (2), pp. 193-205.

" Cucchi, L. e I. Rojkind (2018). Nuevas perspectivas sobre la política argentina entre 1880 y 1916: enfoques, categorías y cronologías. Pasado Abierto 7, pp. 208-215.

"Díaz, A. (1884). El servicio obligatorio: conferencia leída en los salones del 'Club Naval y Militar' en la noche del 20 de febrero de 1884. Buenos Aires: La Penitenciaría.

" Dick, E. (2014). La profesionalización en el Ejército Argentino (1899-1914). Buenos Aires: Academia Nacional de la Historia.

" Domínguez, E. (1898). Colección de Leyes y Decretos militares concernientes al Ejército y Armada de la República Argentina, 1810-1896 (con Anotaciones de Derogaciones, modificaciones, etc.). Tomo Segundo, 1854 a 1880, y Tercero, 1881-1894. Buenos Aires: Compañía Sud-Americana de Billetes de Banco.

" Forte, R. (2003). Fuerzas armadas, cultura política y seguridad interna: orígenes y fortalecimiento del poder militar en Argentina (1853-1943). México: Universidad Autónoma Metropolitana.

" Garavaglia, J. C. (2012). Fuerzas de Guerra y construcción estatal. En J. C. Garavaglia, J. Pro y E. Zimmermann (eds.). Las fuerzas de guerra en la construcción del Estado, América Latina, siglo XIX. Rosario: Prohistoria.

" García Victorica, J. A. (1911). El servicio militar obligatorio bajo sus diversos aspectos. Tesis (doctoral) Universidad de Buenos Aires.

" Gerchunoff, P., F. Rocchi y G. Rossi (2008). Desorden y Progreso, Historia de las crisis económicas argentinas 1875-1905. Edhasa: Buenos Aires. 
" Guembe, M. L. (2015). De la ciudadanía en armas al servicio militar obligatorio. En F. Lorenz (comp.). Las guerras de la historia argentina. Buenos Aires: Ariel.

" Halperin Donghi, T. (1980). Proyecto y construcción de una nación. Argentina (18461880). Caracas: Biblioteca de Ayacucho.

" Macías, F. (2014). Armas y política en la Argentina. Tucumán, siglo XIX. Madrid: Consejo Superior de Investigaciones científicas.

" Macías, F. (2016). El deber de enrolarse y el derecho a votar. Reflexiones en torno a la ciudadanía armada y el sufragio en Argentina, 1863- 1877. Revista de Indias LXXVI:266, pp. 233-258.

" Macías, F. (2018). Orden y violencia política. Argentina 1870-1880. Pasado Abierto 7, pp. 227-240.

" Macías, F. e H. Sabato (2013). La Guardia Nacional: Estado, política y uso de la fuerza en la Argentina de la segunda mitad del siglo XIX. PolHis 11, pp. 20-28.

" Míguez, E. (2011). Mitre Montonero. La Revolución de 1874 y las formas de la política en la organización nacional. Buenos Aires: Sudamericana.

" Ministerio de Guerra y Marina (1881). Disposiciones legales vigentes sobre el Ejército y la Armada de los Estados Unidos. Entresacadas del "Revised Statutes" y traducidas el inglés por Augusto Belín Sarmiento. Secretario de las Comisiones Revisoras de las Ordenanzas Generales del Ejército. Buenos Aires: El Nacional.

" Ministerio de Guerra y Marina (1882). Legislación y organización militar. Proyectos presentados. 1881. Buenos Aires: Establecimiento Tipográfico de 'La Pampa'.

" Ministerio de Guerra y Marina (1887). Memoria del Estado Mayor General del Ejército. 1887. Buenos Aires: La Patria, 2 vols.

" Moroni, M. y J. M. Fernández Espinosa (2007). El reclutamiento para la Guardia Nacional en la Pampa central argentina, 1884-1902. En M. Chust y J. Marchena (eds.). Las armas de la Nación. Independencia y ciudadanía en Hispanoamérica (1750-1850). Madrid y Frankfurt a.M.: Iberoamericana Vervuert.

" Oszlak, O. (1982). La formación del Estado argentino. Orden, progreso y organización nacional. Buenos Aires: Editorial de Belgrano.

" Plotkin, M. B. y E. Zimmermann (2012). Los saberes del estado. Buenos Aires: Edhasa.

" Quinterno, H. (2014). Fuego Amigo: El Ejército y el poder presidencial en la Argentina (1880-1912). Buenos Aires: Teseo.

" Rabinovich, A. (2013). La société guerrière. Pratiques, discours et valeurs militaires dans le Rio de la Plata, 1806-1852. Rennes: PU Rennes.

"Sabato, H. (1998). La política en las calles. Entre el voto y la movilización. Buenos Aires, 1862-1880. Buenos Aires: Sudamericana.

"Sabato, H. (2008). Buenos Aires en armas. La revolución de 1880. Buenos Aires: Siglo XXI.

" Sabato, H. (2016). Fuerzas armadas y federalismo en la Argentina del siglo XIX. La conflictiva relación entre nación y provincias en materia militar. En M. Suárez Cortina (ed.). Federalismos. Europa del Sur y América Latina en perspectiva histórica. Granada: Ed. Comares.

"Sarmiento, D. F. (1902). Obras Completas, Tomo 51. Buenos Aires: Establecimiento Poligráfico Márquez, Saragoza y Cía.

"Sommariva, L. (1931). Historia de las intervenciones federales en las provincias. Tomo 2. Buenos Aires: El Ateneo. 
"Soprano, G., M. L. Guembe y R. J. Laleff Ilieff (2012). Debates legislativos y leyes sobre la defensa nacional y las Fuerzas Armadas. Un análisis comparado en tres períodos de la historia política argentina: 1895-1916, 1946-1955 y 1983-2001. Ponencia presentada en VII Jornadas de Sociología de la Universidad Nacional de La Plata. Consultado en línea en http://jornadassociologia.fahce.unlp.edu.ar/ (10/10/2019)

"Zimmermann, E. (1995). Los liberales reformistas. La cuestión social en la Argentina (1890-1916). Buenos Aires: Sudamericana - Universidad de San Andrés. 